\title{
Empathy can be taught: communication training builds upon our innate sense of others
}

\author{
Susannah L. Rose ${ }^{1}$, Serena F. Wiseman ${ }^{2}$ \\ ${ }^{1}$ Office of Patient Experience \& Center for Bioethics, Clinical Transformation, Cleveland Clinic, Cleveland Clinic Lerner College of Medicine at \\ Case Western Reserve University, Cleveland, Ohio, USA; ${ }^{2}$ Office of Patient Experience, Clinical Transformation; Cleveland Clinic, 9500 Euclid \\ Avenue, Cleveland, Ohio, USA \\ Correspondence to: Serena F. Wiseman, BS. Office of Patient Experience, Clinical Transformation; Cleveland Clinic, 9500 Euclid Avenue, Cleveland, \\ Ohio 44195, USA. Email: wisemas@ccf.org. \\ Comment on: Kerbauy D, Santalucia C, Caldana R, et al. Communicating with HEART around the globe—does empathy transcend culture? J Hosp \\ Manag Health Policy 2019;3:30.
}

Received: 02 March 2020; Accepted: 28 March 2020; Published: 25 June 2020.

doi: 10.21037/jhmhp-2020-06

View this article at: http://dx.doi.org/10.21037/jhmhp-2020-06

Kerbauy et al. describe the deployment of a communication skills training course at the Fleury Group. The Training was based upon the Communicate with H.E.A.R.T. program developed and used at Cleveland Clinic, and the authors focused upon START with Heart-an upfront customer service class-to determine if it might serve as a means to provide culture change to improve the experience for their patients. The authors evaluated the training by using interviews with leaders at Fleury, and by conducting observations, as they describe in their article entitled "Communicating with HEART around the globe-does empathy transcend culture?" (1). As employees of the Cleveland Clinic, we have participated in Communicate with H.E.A.R.T. classes and have seen the positive influence this training has had on the culture at the Cleveland Clinic. We are pleased to see it being used and evaluated in a different healthcare system in Brazil.

The fundamentals of S.T.A.R.T. with Heart, which include: smiling, engaging with the patient on a personal level, active listening, establishing a positive rapport and thanking the patient for their time, speaks to the core necessity of human beings to engage on an interpersonal level regardless of culture.

"6 Things you need to know about Empathy" by Peg Streep (2), states "Research shows that most people think of empathy as intuitive..." however, "The best way to think about empathy is [as] an innate capacity that needs to be developed, and to see it as a detail in a larger picture." She points out that the ability to think empathically is imbued during infancy. Once the infant has their "emotional states recognized and responded to, the groundwork is laid not just for the child's sense of self but sense of other. In time, that seed grows into empathy and the capacity for intimate connection". Teaching empathy is, for lack of a better phrase, tapping into a "sense of other" that each of us possesses from our earliest experiences.

The foundation for feeling empathy described by Streep might also explain why empathy is so effective as a deescalation tool for a patient in distress. Each of us, it seems, developed a sense of empathy from the earliest stages of our lives.

The S.T.A.R.T. with HEART class teaches the behaviors that model "expressing empathy". Regardless of the employees' personal feelings; if they are genuinely role modeling and conveying these behaviors, the recipient (patient) translates these behaviors as an expression of empathy, which allows the beginning of a genuine relationship to ensue. The need for these genuine connections is particularly exquisite in the healthcare environment, as the individual entering into the healthcare system is often under tremendous stress. By fostering empathy among all employees, patient experience will almost certainly improve. This is important for three reasons: (I) treating people with empathy is the right thing to do; (II) empathic communication can foster positive therapeutic relationships and trust; (III) making patients feel seen and heard can foster loyalty to the hospital system, 
which may align with organizations' business interests.

The effectiveness of relationship building by caregivers can be illustrated by the story of a patient we will name Betty. Several years ago, Betty came to Cleveland Clinic from out of state to undergo surgery. Betty was an immigrant with a fairly good command of the English language. The day of surgery Betty was in good spirits. However, she was very frightened and appeared to be experiencing some confusion. When she was transferred from the cart to the OR table, she was given medication to relax her, but she remained in a semi-conscious state. She overheard a conversation that frightened her, drastically increased her stress level and created a very upsetting experience.

During recovery she was still very upset by the conversation and shared her feelings to the team caring for her. The team did not immediately show empathy. Rather they started to challenge the accuracy of her memory because she had been "confused and medicated". Betty continued to share the experience with more and more caregivers, as she did not feel as though people were listening to her and being empathetic.

Our team met with Betty and employed the Communicate with HEART behaviors. Upon conclusion of the discussion and a very small amount of follow-up, Betty indicated that she felt a huge weight had been lifted since someone had truly heard her concerns. Betty felt empathy through demonstration of the Communicate with HEART behaviors, which included verbally expressing the emotions that she had been feeling. Nine years later, the team member who worked closest with Betty continues to receive follow-up contacts from her, as she commemorates the anniversary of the event where she received the Communicate with HEART behaviors with an appreciation phone call or visit. The empathy that she received was that impactful.

Future work in this area should formalize research evaluations, to be able to achieve greater clarity about how communication training can impact empathy in healthcare. For example, the book called "Compassionomics: The Revolutionary Scientific Evidence that Caring Makes a Difference" written by Trzeciak and Mazzarelli outlines the research that has been done in this field, and provides excellent examples of how empathy and compassion research can be expertly conducted in healthcare (3). We suggest that research should not only focus upon the impact of empathy on patients and employees, but such research might also focus on business goals, such as patient loyalty to the organization, cancelled appointments and no-shows, and employee retention.

\section{Acknowledgments}

Mary Beth Mercer, MPH assisted with final edits. Funding: None.

\section{Footnote}

Provenance and Peer Review: This article was commissioned by the Editorial Office, Fournal of Hospital Management and Health Police. The article did not undergo external peer review.

Conflicts of Interest: Both authors have completed the ICMJE uniform disclosure form (available at http:// dx.doi.org/10.21037/jhmhp-2020-06). SLR has received speaking honorariums and travel funding in the past 3 years from Siemens Healthineers, Healthcare Information and Management Systems Society, Inc. (HIMSS), Next Generation Patient Experience (NGPX), and healthcare systems in Sweden and Saudi Arabia on topics related to public health, bioethics and health policy. She served on the Ethics Committee for the American Society of Clinical Oncology (ASCO), a non-profit professional organization in the USA, for a 2-year term ending in fall 2019, and they paid for her travel to and from bi-annual meetings. None of these relationships has a direct or indirect relationship with the content of this manuscript. None of these relationships is related to the work in this manuscript. The other author has no conflicts of interest to declare.

Ethical Statement: The authors are accountable for all aspects of the work in ensuring that questions related to the accuracy or integrity of any part of the work are appropriately investigated and resolved.

Open Access Statement: This is an Open Access article distributed in accordance with the Creative Commons Attribution-NonCommercial-NoDerivs 4.0 International License (CC BY-NC-ND 4.0), which permits the noncommercial replication and distribution of the article with the strict proviso that no changes or edits are made and the original work is properly cited (including links to both the formal publication through the relevant DOI and the license). See: https://creativecommons.org/licenses/by-nc-nd/4.0/. 


\section{References}

1. Kerbauy D, Santalucia C, Caldana R, et al. Communicating with HEART around the globe-does empathy transcend culture? J Hosp Manag Health Policy 2019;3:30.

2. Streep P. 6 Things You Need to Know About Empathy.

doi: 10.21037/jhmhp-2020-06

Cite this article as: Rose SL, Wiseman SF. Empathy can be taught: communication training builds upon our innate sense of others. J Hosp Manag Health Policy 2020;4:10.
Psychology Today, January 23, 2017. Available online: https://www.psychologytoday.com/us/blog/techsupport/201701/6-things-you-need-know-about-empathy

3. Trzeciak S, Mazzarelli A. Compassionomics: The Revolutionary Scientific Evidence that Caring Makes a Difference. 1st edition. Studer Group, 2019. 